\title{
Energy sources in gynecologic laparoscopic surgery
}

\author{
Nikolaos Kathopoulis, Athanasios Protopapas, Ioannis Xatzipapas, Panagiotis Antsaklis, \\ Dimitrios Zacharakis, Konstantinos Samartzis, Konstantinos Kipriotis, Dimitrios Loutradis
}

\author{
$1^{\text {st }}$ Department of Obstetrics and Gynecology, Kapodistrian University of Athens, Alexandra Hospital, Athens, \\ Greece
}

\section{Corresponding Author}

Kathopoulis Nikolaos, Academic fellow, $1^{\text {st }}$ Department of Obstetrics and Gynecology, University of Athens, Alexandra Hospital 13-15 Sotiros Street, 18535, Piraeus, Greece, email: doctor@kathopoulis.gr,

\begin{abstract}
A number of energy sources are used in gynecologic laparoscopy. Monopolar electrosurgery, bipolar electrosurgery, advanced bipolar devices, ultrasonic energy and various types of lasers are some of the technologies used nowadays to facilitate surgeons tasks during laparoscopic operations. A lack of basic knowledge or ignorance of principles of electrosurgery and equipment among obstetricians and gynecologists is reported. As a result thermal injuries during laparoscopic electrosurgery occur, which frequently lead to significant morbidity and mortality and medicolegal actions. It is important though that surgeons have an understanding of the biophysics of these technologies in order to understand their limitations and potential dangers and to utilize the most appropriate energy source in the appropriate clinical setting to minimize the risk of a potential complication. This review provides an overview of the basic principles of these energy sources, the tissue effects and the complications that may arise. It aims to highlight any potential advantages or disadvantages of various energy sources and help surgeons to achieve better knowledge of their instrumentation.
\end{abstract}

Key words: Energy sources, electrosurgery, gynecologic laparoscopy, thermal injuries

\section{Introduction}

Minimally invasive surgery has undergone significant advances and has changed the way operations are performed in the field of gynecology and its sub specialties. The advances of minimally invasive surgery are well documented: faster recovery, shorter hospital stay, rapid return to normal activities, fewer postoperative infections, less pain and better cosmetic results ${ }^{1}$. Hemostasis is essential during laparoscopic operations to ensure a clear view of the operating field and reduce the possibility of converting to an open procedure. Various methods like clips, sutures and stapling devices are available for achieving hemostasis but their use has gradually been abandoned due to difficulty with repeated 
applications, cost and problems of displacement. On the other hand monopolar or bipolar energy are widely used in daily clinical practice due to low cost, reusability and availability. Moreover the use of new generation energy sources is steadily increasing. Advanced bipolar devices with tissue feedback monitoring and devices that use ultrasonic technology may be used for dissecting tissue planes, ligate and seal vessels or safely transect tissue. These versatile devices can reduce the number of instruments and instrument changes during surgery, are very ergonomic and shorten the duration of surgery.

Althoughelectrical energy is the most commonly used energy in operating rooms it is surprising the lack of basic knowledge and ignorance of the principles of electrosurgery among surgeons that use these devices ${ }^{2}$. In a very interesting study 20 specialists in obstetrics and gynecology were selected and their practical and theoretical skills were evaluated in present time and 1 year after the initial assessment. No candidate successfully completed the written test and the pass rate was $18 \%$ in the second test ${ }^{3}$. And this is not a only a problem of young minimally invasive surgeons as even very experienced surgeons have knowledge gaps in the safe use of widely used energy based devices. In a pioneer study 48 SAGE (Society of American Gastrointestinal and Endoscopic Surgeons) leaders were asked to participate on a 11 item multiple choice examination concerning safe energy use the median percent of correct answers was $59 \%{ }^{4}$. It is clear that in order to use energy devices to their fullest potential and prevent complications surgeons need to understand the mode of actions of each device and its potential pitfalls. Education on the principles of electrosurgery is important before entering the operating room in order to minimize the relatively common electrosurgical complications ${ }^{5}$.

In this review we present the basic biophysics and principles of the various energy sources so far used in gynecologic laparoscopic operations.

\section{History of electrosurgery}

The idea of hemostasis with heat has an origin from prehistoric years when heated stones were for cauterization and from ancient Egypt that heated oil was used for the same purpose. Electrosurgery on the other hand is the application of alternating current to biological tissue to achieve effects like cutting and coagulation and was first reported by Becquerel in the early $19^{\text {th }}$ century. He used non-alternating current to heat a wire needle and achieve hemostasis when applying to tissue. In 1891, the French biophysicist D'Arsonoval showed that it was possible to pass high frequency alternating current $(>20 \mathrm{kHz}$ ) through the body without causing an electric shock ${ }^{6}$. It was in 1926 that at Peter Bent Bringham Hospital that we have the first application of electrosurgery with the electrosurgical generator designed by William Bovie. The neurosurgeon Harvey Cushing removed a tumor from a patient's head minimizing the bleeding with the aid of electrosurgery ${ }^{7}$.

\section{Basic principles of electrosurgery}

Electricity is the flow of electrons through a conductor. Current (I) is defined as the flow of electric charge and is measured in Amperes. Voltage (V) is the electromotive force that forces the "current" through the conductor and is measured in Volts. Resistance (R) is the impedance of the conductor to the flow of the electric current and is measured in Ohms.

Electrosurgery is governed by the Ohm's law:

Current (I) (amps) = Voltage (V)(Volts)/Resistance (R) (Ohms)

Resistance depends upon the type of target tissue and is inversely proportional to the salt (water) content of the tissue. Blood has least resistance and bone the most. The higher the force (voltage) that pushes the electrons, the faster they will flow and the higher the current will be. The voltage is supplied by an electrical generator. The electrons that flow in an electrical circuit are not consumed, they follow 
the path of least resistance and will return to the positive pole of the voltage source or to the ground ${ }^{8}$.

The total amount of energy delivered to the tissue is the product of voltage and current. It is measured in watts

\section{Energy (W)= Voltage (V) x Current (I)}

The electrosurgical effects are brought in the target tissue through the conversion of electrical energy into heat. The Joule's law of thermodynamics governs this where amount of heat is the product of the square of current, the voltage and the time of application $(\mathrm{t})$

Heat $(\mathrm{H})=$ Current $^{2}\left(\mathrm{I}^{2}\right) \times$ Voltage $(\mathrm{V}) \times$ Time $(\mathrm{t})$

The basic principle of electrosurgery is that the circuit must be completed. The current generated from the electrosurgical generator will reach the target tissue through the active electrode and will return to the generator. The 3 basic components of electrosurgery are therefore electrosurgical generator, active and passive electrode.

\section{Electrosurgical generator}

The electrosurgical generator converts the electric current from the low frequency electrical power outlets $(60 \mathrm{~Hz})$ to a high frequency electric current $(>100 \mathrm{kHz})$, so it can not cause nerve and muscle stimulation. All generators are programmed to deliver power in watts, however the effect of the active electrode on tissue is also dependent on the time it is applied on the tissue. This way there is a circuit involving the generator, active electrode, patient and return electrode. The older electrosurgical generators used to be ground referenced systems, but this way the current could return to the ground by any metallic object touching the patient causing alternate site burns like ECG electrodes, IV fluid stand, IV line poles etc. Modern generators are isolated systems in which the therapeutic current is isolated from the power current by a transformer. The therapeutic current must return to the electrosurgical unit itself to complete the circuit. The result is virtually elimination of current diversion and alternate site burns ${ }^{9}$.

\section{Tissue effects of electrosurgery}

The electrical current is generated by the electrosurgical unit and it travels through the target tissue via the active electrode to produce heat. The heat produces the desired effects at the tissue. As the tissue temperature rise to between 34 an $44{ }^{\circ} \mathrm{C}$ there is edema and tissue inflammation. From 44 to $50^{\circ} \mathrm{C}$ there is enzyme denaturation and between $50-80{ }^{\circ} \mathrm{C}$ coagulative necrosis. Between 80-100 ${ }^{\circ} \mathrm{C}$ tissue dessication and $>100{ }^{\circ} \mathrm{C}$ the water inside the cells evaporates and cell walls explode. Higher temperatures result to vaporization due to hydrocarbon combust.

\section{Effects of electrosurgery:}

1. Cutting: It is the effect provided from the "pure cut" mode of the electrosurgical unit. It is a continuously delivered $100 \%$ of the time, low voltage and high current waveform which results in a rapid temperature elevation more than $100^{\circ} \mathrm{C}$. Explosive vaporization of intracellular fluid and ionization of the gas released produces a clear cutting action dividing the tissue with minimal lateral spread ${ }^{10}$.

2. Superficial Coagulation or fulguration: It is the effect from the "pure coag" mode of the unit. It is an interrupted delivered $6 \%$ of the time high voltage low current waveform that produces sparks results in slow temperature increase. This results in protein denaturation and formation of coagulum but greater lateral thermal spread. Fulguration is possible in monopolar electrosurgery and when the electrode is not in contact with the tissue and results in superficial necrosis and eschar formation ${ }^{11}$.

3. Deep coagulation or desiccation: It results when active electrode and tissue are in contact. Tissue is heated and the water in the cell boils to steam, resulting in a drying out of the cell. Desiccation can be achieved with either the cut or coag mode 
by contact of the electrosurgical device with the tissue and no spark formation ${ }^{12}$.

Except from "pure cut" and "pure coag" mode many generators provide a blended current that does not result from combined cutting and coagulating waveforms as is commonly thought. The blended waveform is pulsatile release of current between $6 \%$ and $100 \%$ of the time at variable intervals. By convention in blend 1,2 and 3 found in most electrosurgical generators current is delivered in 50\%, $40 \%$ and $25 \%$ of the time respectively. This way the proportion of time the current flow is interrupted can be adjusted using various "blend" settings. (Figure 1)

Other factors that may influence the tissue effect of electrosurgery are size and shape of electrode, time of electric application, tissue resistance and whether the electrode touches or not the tissue.

\section{Monopolar electrosurgery}

Monopolar systems are widely used in daily clinical practice in gynecologic laparoscopy. Current flow proceeds from the active electrode to the tissue, spreads throughout the rest of the body and exits through the passive or return electrode returning to the electrosurgical generator. The return electrode is located on the patient at a site away from the surgical site. As the electrical energy spreads out, the current density is diffuse and the tissue is not heated. The active electrode may be shaped as needle, hook or ball and the effect produced depends on the area of contact with the tissue, current density, type of waveform, water content of the tissue applied and time of application. The return electrode must be applied to a wide area of good conducting tissue like muscle avoiding bony prominences. The current density on the return pad is inversely proportional to the area in contact with the tissue so it must be as large as possible and in good contact. In cases of incompletely applied ground pad there is large concentration of electron flow that may result in tissue damage from heat. (Figure 2)

\section{Bipolar electrosurgery}

Bipolar electrosurgery is only involving a small amount of tissue in the circuit. There is no return plate, the return electrode is adjacent to the active electrode, and current flows only between them. Therefore the patient is not a part of the circuit, the

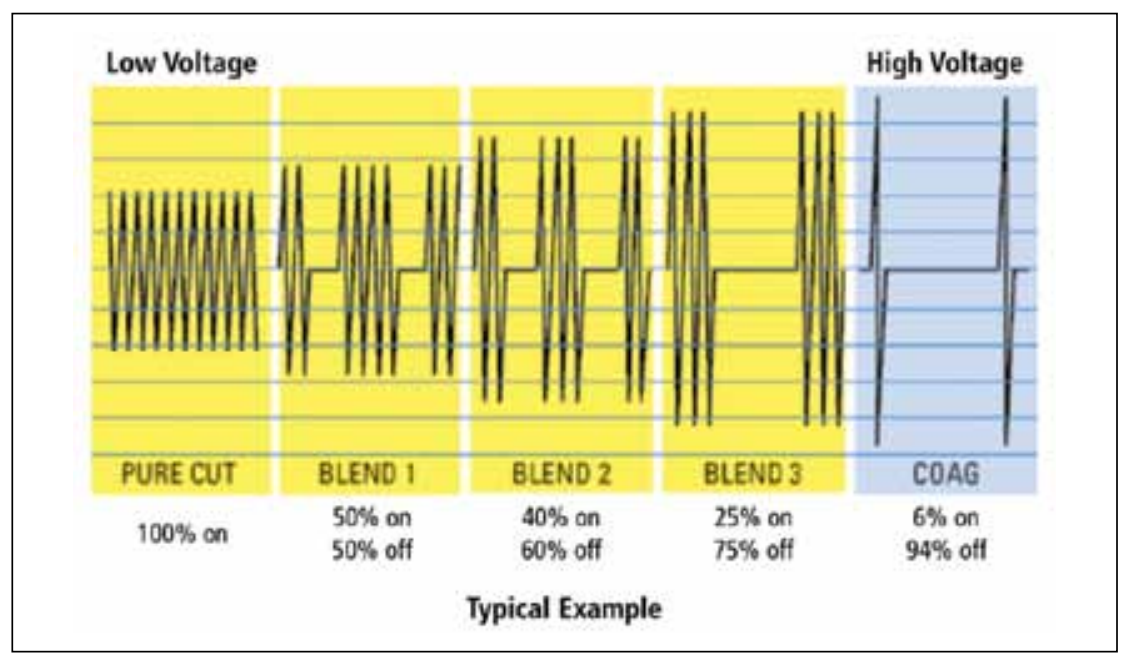

Figure 1. Waveforms of a typical Electrosurgical Unit. 


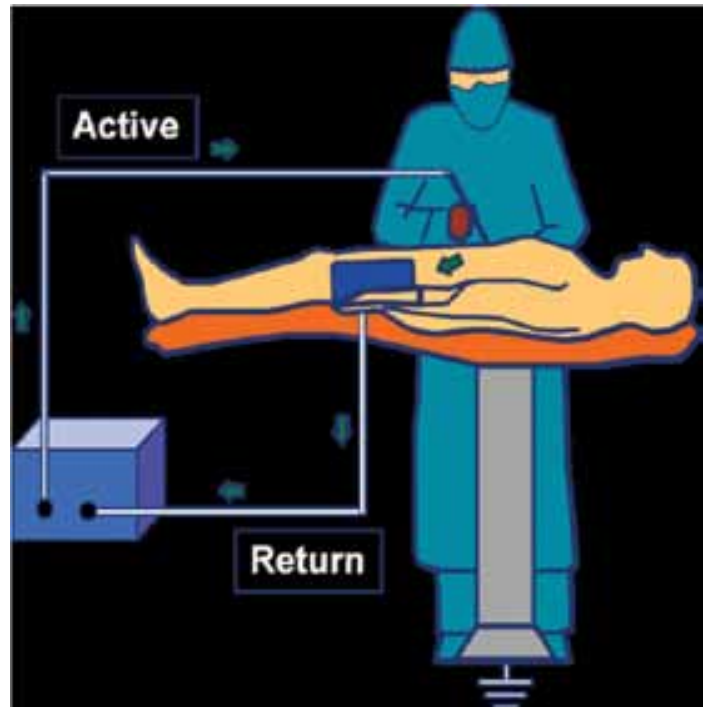

Figure 2. Monopolar circuit ${ }^{9}$.

current passes between the tips of the instrument and only affects tissue grasped between electrodes. Bipolar devices are relatively safe compared to monopolar as it causes minimum collateral spread, reduces risk of interference with other devices and better coagulation ${ }^{13}$. Moreover desired tissue effect may be achieved with lower voltage due to the low tissue impedance resulting from the close proximity of the electrodes.

Desiccation is the thermal effects produced by the bipolar devices and it seemd superior their monopolar counterparts. In addition the close proximity of 2 electrodes in bipolar instruments virtually eliminates the threats of alternate site burns as well as direct and capacitive coupling that we will discuss later. However prolonged activation of the electrode may generate significant heat and cause injury to other tissues upon contact ${ }^{14}$.

Major disadvantage of bipolar is that it cannot cut tissue although a "cut" waveform is applied. Vaporization and fulguration are inefficient and in order to transect the desiccated tissue we need to change instruments inducing this way the operating time. In addition sometimes tissues become adherent to the electrodes and disengagement may cause tearing of blood vessels. This occurs when there is excessive dehydration of tissues and charring. Release tissue before bipolar energy application is terminated is the solution to this practical issue ${ }^{15}$ (Figure 3 ).

\section{Advanced bipolar devices}

The last years, new generation bipolar devices have been developed to seal vessels up to $7 \mathrm{~mm}$ diameter ${ }^{16}$. These are basically bipolar forceps based on three factors: compression, time and temperature. The electrosurgical generator of the vessel sealer, that is unique for every instrument, generates the current between the jaws of the instrument resulting in increased temperature up to $60-100{ }^{\circ} \mathrm{C}$. The generator uses controlled tissue feedback response systems that senses tissue impedance in order to continuously adjust the voltage and current generated by the unit. The increased temperature causes denaturation of hydrogen bonds in tissue proteins.

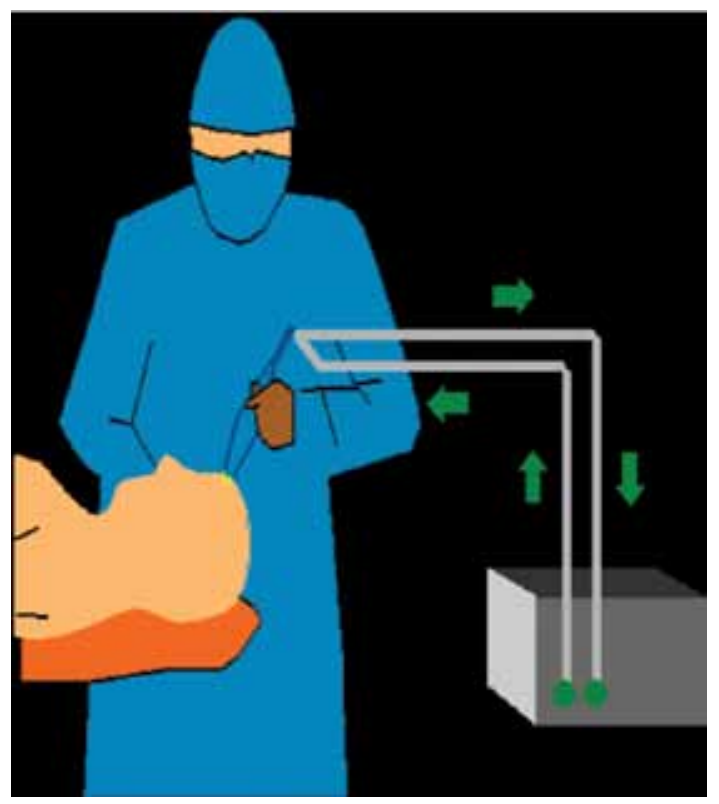

Figure 3. Bipolar circuit ${ }^{9}$. 
The pulsatile energy delivered from the feedback mechanism of the device permits the tissue to cool and during this phase hydrogen bonds reform with a different configuration result in formation of a tissue glue which seals the walls of the vesse ${ }^{17}$. The systems also inform the surgeon with an audio signal that vessel sealing has been achieved minimizing this way lateral thermal spread associated with prolonged device activation.

LigaSure was the first system commercially available. The concomitant use of recently released ForceTriad generator permits to monitor impedance change of the tissue 4000 times per second and the energy is delivered in pulses allowing the tissue to $\mathrm{cool}^{18}$. The handpiece of the system has a ratchet that allows calibrated force to be applied to the tissue. The strong seal formatted can withstand pressures up to $550 \mathrm{mmHg}$. The LigaSure can seal vessels up to $7 \mathrm{~mm}$ with low lateral thermal spread ${ }^{19}$ (Figure 4).

EnSeal is a bipolar device that shares the same electrical generator of Harmonic scalpel. The handpiece uses a proprietary electrode that contains millions of conductive nanoparticles, embedded in a temperature-sensitive matrix. The temperature is maintained at around $100{ }^{\circ} \mathrm{C}$ as the microparticles are separating apart when the temperature exceeds this limit and they are rendering thereafter non-conductive. The instrument also has a cutting mechanism incorporated into the device. The latest

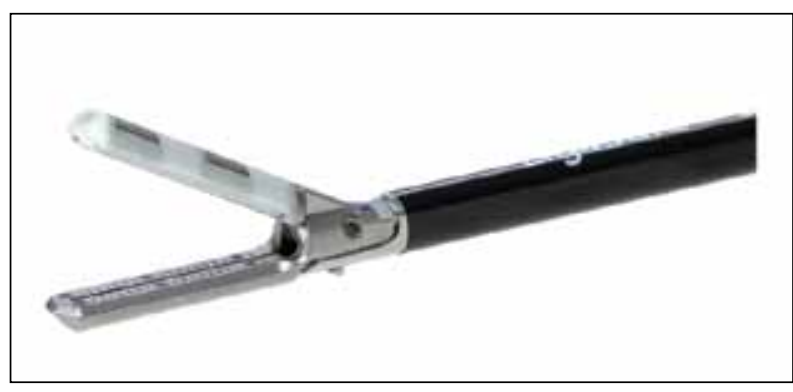

Figure 4. Ligasure. advance is the EnSeal G2 articulating hand piece. When the vessels are clamped perpendicularly the blood flow is completely interrupted and theis preserves the current density and obviates the cooling effect from heat conduction through blood flow. If a $7 \mathrm{~mm}$ vessel is clamped obliquely at an angle more than $90^{\circ}$, the effective diameter of the vessel becomes more than $7 \mathrm{~mm}$, which is beyond the range of most vessel sealers. In the EnSeal articulated handpiece, the tip can be rotated to facilitate perpendicular tissue clamping ${ }^{20}$ (Figure 5).

The PlasmaKinetic system delivers pulsed energy with continuous feedback control. The pulsatile delivery of energy allows tissues to cool between energy bursts, reducing tissue drying at the contact point and therefore resulting in less electrode sticking. It also incorporates a retractable blade into the jaws in order to cut the tissue after vessel sealing. This may reduce "instrument traffic" during laparoscopy and reduce operative times and hospital costs ${ }^{21}$.

All these devices share a common disadvantage the bulky instrument tip compromising their dissecting capabilities. Manufacturers have tried to modify the tips to more curved and pointed instruments but there are concerns that a smaller surface could affect the quality of vessel sealing. For these reasons many surgeons continue to use traditional monopolar scissors or conventional bipolar graspers for their superior dissecting capabilities.

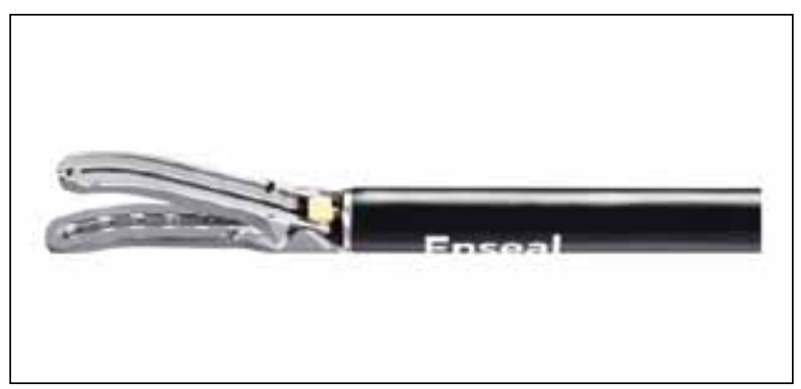

Figure 5. Enseal bipolar device. 


\section{Ultrasonic devices}

Ultrasonic laparoscopic energy sources are able to seal vessels and transect tissues. Most of the tissue effects are the same as those for bipolar devices but they are produced without the passage of electrical current through the patient or the tissue. The principle of ultrasonic energy is conversion of electrical energy into mechanical and thermal energy via ultrasonic vibrations to achieve tissue transection and vessel sealing ${ }^{22}$. The electrical current is delivered to the handpiece that has a piezoelectrode that convert electric energy to vibrating ultrasonic energy at frequencies from 23 to $55 \mathrm{kHz}$. The shaft of the instrument, the active component of the device is in contact with the cylinders and oscillates linearly at the same frequency. The active blade vibrates over $50-100 \mu \mathrm{m}$ at frequency of $55.5 \mathrm{kHz}^{23}$. Ultrasonic tissue transection occurs as a result of mechanical friction between the oscillating device shaft and the tissue. In addition to mechanical friction, "cavitation effect" may facilitate transection. Cavitation is the phenomenon that occurs during tissue vaporization and the steam released from vaporized cells expands existing tissue planes, assisting dissection ${ }^{24}$. Vessel sealing tissue effects are the same with those obtained by advanced bipolar electrosurgery: desiccation, coagulation and coaptation. However the mechanism by which they are obtained is different. With electrosurgery electrical energy is converted to mechanical energy to thermal energy via intracellular frictional effects. With ultrasonic energy, electrical energy is converted to mechanical to thermal energy as the frictional force exerted on the tissues by the oscillating shaft tip results in sequential extracellular heating followed by intracellular heating ${ }^{25}$ (Figure 6).

There are so far a few ultrasonic devices. The Ultracision Harmonic Scalpel was developed to seal vessels up to $3 \mathrm{~mm}$ in diameter ${ }^{26}$. The Harmonic ACE was subsequently developed and approved to seal vessels up to $5 \mathrm{~mm}^{27}$. Harmonic ACE+ is the latest developed instrument that uses "adaptive tissue technology" to regulate energy delivery according to tissue conditions, may seal vessels up to $7 \mathrm{~mm}$ and provides an audio signal to the surgeon to minimize thermal spread ${ }^{28}$. AutoSonix, Sonocision and Sonosurg are other examples of currently available laparoscopic devices that operate at similar frequencies to the Harmonic ACE and seal vessels up to $5 \mathrm{~mm}$. Sonicision has the advantage of cordless handpiece and is claimed to generate less tissue plume.

Advantages of ultrasonic vessel sealers included less tissue necrosis and charring, reduced lateral thermal spread and less smoke generation compared with electrosurgery ${ }^{29}$. Tissue temperature is less than $100^{\circ} \mathrm{C}$ and therefore tissue charring is much less than monopolar electrosurgery but similar to advanced and conventional bipolar electrosurgery ${ }^{30}$. The smoke plume generated by ultrasonic vessel sealers is less than other laparoscopic energy sources but smoke from these devices may significantly obscure the surgeon's view ${ }^{31}$. General disadvantages of ultrasonic devices include slower coagulation compared with electrosurgery, excessive applied pressure and altering of the frequency or the impedance of the instrument due to blade fatigue leading to temperature elevation ${ }^{32}$. The tip of the active blade needs to be

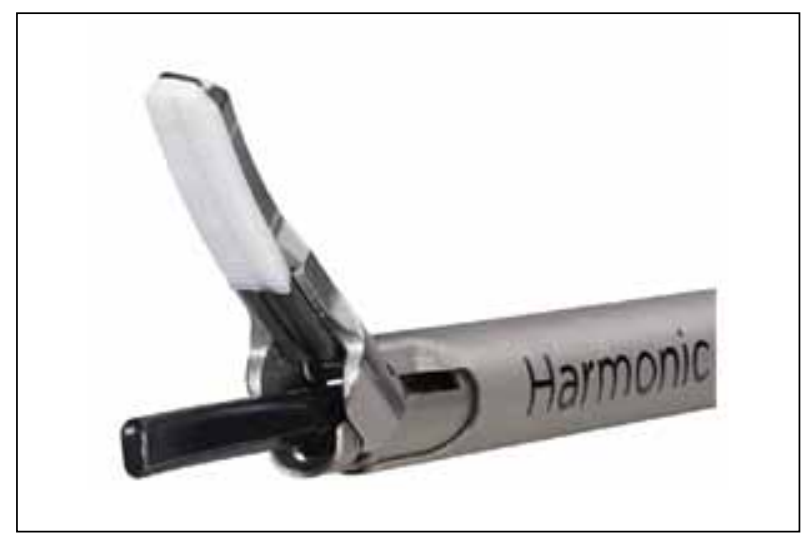

Figure 6. Harmonic ACE+. 
always under vision and never touch visceral organs immediately after activation as there is danger of serious thermal damage due to high temperatures.

Finally the Thunderbeat is the first device to integrate both ultrasonically generated frictional heat energy and advanced bipolar energy in one instrument. It can rapidly cut and precisely dissect tissue while advanced bipolar technology provides vessel sealing up to $7 \mathrm{~mm}$ diameter with minimal thermal spread.

\section{Laser (Light Amplification by Stimulated Emission of Radiation)}

Laser is an energy source that does not include electrical current. By amplifying light of specific wavelength, the device emits a beam of photons with a high degree of spatial and temporal coherence, which is dependent on the physical properties of the different components within the laser device. The tissue effects obtained depend on exposure time and power density adjustment. The power settings and the spot size of the laser beam may influence power density. There are a number of different types of lasers: CO2, argon, Nd: YAG, KTP-532 with different properties. The advantages of laser are the accuracy of targeting tissues and lack of lateral thermal spread. In gynecology they are mainly used for endometriosis ablation as they are not absorbed by unpigmented tissues and thus abnormal tissues are preferably coagulated ${ }^{34}$.

\section{Plasma Surgery}

The device has a $5 \mathrm{~mm}$ handpiece that can deliver argon neutral plasma energy. The system is electrically neutral and no ground pad is necessary. Plasma is th fourth state of matter after solid, liquid and gas. When energy is provided to a solid, it melts to form liquid and then evaporates to form gas. If extra energy is provided then gas is ionized and becomes plasma which is unstable and gives up to energy in
3 forms: light that illuminates target area, heat that coagulates tissue and seal small vessels and kinetic energy that vaporizes tissues of various densities including the fibrosis od deep endometriosis. The origin of plasma energy idea comes back on 1970s but it was not until late 1990s that a multielectrode system that generated plasma with a higher power density using a low level of current was invented. That design resulted to Plasmajet system that is commercially available nowadays. It is mainly used for the treatment of endometriosis because of better preservation of ovarian follicles ${ }^{36-37}$ (Figure 7).

\section{Laparoscopic Energy source related injuries \\ Monopolar electrosurgery injuries}

Alternate site burns: Accidental burns may occur from accidental activation of the active electrode when it was not in use and not placed in an insulated holster. This way the electrode could burn through the sterile drapes and result in a severe burn of the patient. Moreover in case of flammable sterile drapes or fluids, a fire in an operating room is not impossible to happen ${ }^{38}$.

The older grounded electrosurgical generators has

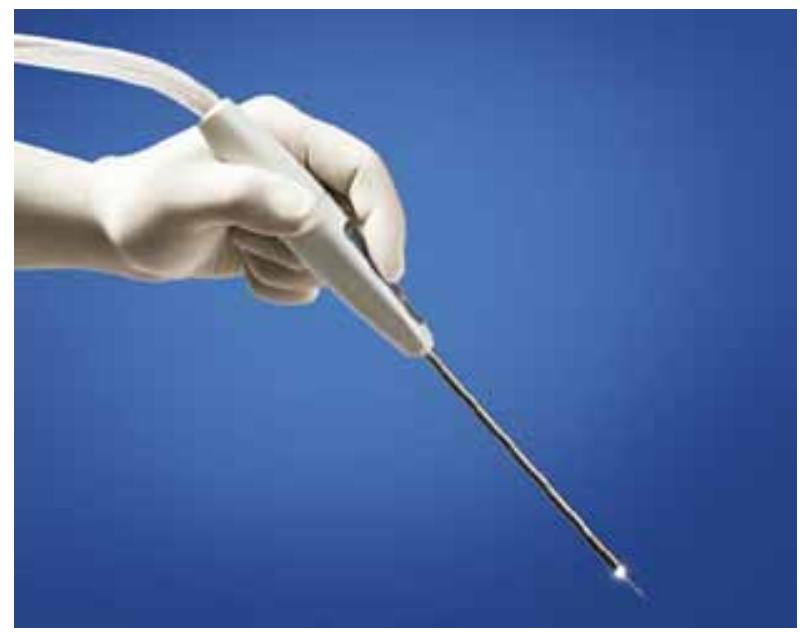

Figure 7. PlasmaJet handpiece. 
a design flaw that was predisposing to alternate site burns. The electrical current could flow through the patient and not return to ground via the operating table but was directed through other sites such as Electrocartiogram leads or pads. The invention of isolated electrosurgical generators eliminated this problem as the electrical current was conducting back to the generator via the return $\operatorname{pad}^{39}$. On the other hand this solution created a new problem of burns on the return pad in case of defective attachment to the body or manufacture defect. In these circumstances higher current density could concentrate in the small area of detached electrode pad and result in serious burn to the patient. The introduction of "Contact Quality Monitoring" technology could prevent this type of injuries. It consists of a dual section dispersive electrode which is continuously monitoring the total impedance of the electrode. In case of impedance increase during the procedure the CQM circuit detects it and automatically inhibits electrosurgical units output ${ }^{40}$.

Insulation failure: Insulation failure is a common electrosurgical injury and has a high probability of causing full thickness intestinal thermal injury. Damage to the insulation of the active electrode provides an alternate pathway for the current to enter the patient unknown to the surgeon. The power density on insulation failure sites is very high and so the temperature increase $\left(700^{\circ} \mathrm{C}-1000^{\circ} \mathrm{C}\right)$. Physical insult, mechanical degradation, cleaning, repeated sterilization, high-voltage use and manufacture defects are some of the reasons of insulation failure ${ }^{41}$. Concerning the prevalence of insulation failure Montero et al. reported 33/226 (15\%) of instruments checked in their study had insulation failure ${ }^{42}$. Moreover in a similar study in Australia Yazdani et al identified $29 \%$ of monopolar and $15 \%$ of bipolar instruments to be defective with insulation failure ${ }^{43}$. A number of measurements have been applied in order to minimize this hazard such as routine inspection of the instruments, testing or use of disposable material. They have been proven ineffective as the sensitivity of detecting an instrument with insulation failure is only $10 \%$. Even disposable instruments may have up to $3 \%$ insulation failure.

Active Electrode Monitoring (AEM) is the technology that offers combination of extra electrical insulation, conducting shield and an electronic current monitoring system. The system can detect stray energy from insulation failure, capacitive coupling and direct coupling at the same time with its feedback mechanism, alert the surgeon and interrupt further supply of energy eliminating the risk of stray energy complications ${ }^{44}$.

Capacitive coupling: Capacitive coupling is the transfer of energy to a conductive material through intact insulation of the laparoscopic instrument. The capacitor is created when 2 conductors are separated by an insulator. Capacitive coupling injuries were common with the use of "hybrid trocars" that consisted of a metal cannula with a surrounding plastic anchor, and the trapped capacitive current to the trocar could arc to surrounding tissues or instruments ${ }^{45}$. The use of noncontact surgical technique, higher electrosurgical settings and single port laparoscopy predispose capacitive coupling injuries. The use of AEM technology offers an excellent solution to this problem ${ }^{46}$.

Direct coupling: Direct coupling occurs when the active electrode comes in contact with another metal instrument or object that is in contact with tissues away from the active electrode and results in thermal injury. The laparoscope and the suction/ irrigation tube are the most common instruments for the occurrence of direct coupling. Direct coupling to an adjacent instrument is caused by technique and not instruments design or defect so surgeon must be very careful in monopolar use. The entire portion of the electrode tip should be in visual contact when applying energy in order to minimize this kind of complication.

\section{Laser complications and other sources common complications}

With the use of lasers there is always a concern about the possibility of ignition of flammable materials and accidental eye injuries. Laser beams may also reflected by surgical instruments in the operating 
field and provoke injuries of nontargeted tissues.

Even though bipolar, lasers and ultrasonic energy avoid the passage of electrical stray currents trough the patient, all these devices exert their action to the tissues through thermal energy. Lateral thermal spread is always a concern of all these devices even the manufacturers often claim

\section{Comparison of different energy sources}

There are many reasons for a surgeon to prefer a particular laparoscopic energy source. The most common is surgeon's own experience that may have been preordained by his mentor during surgical training. Moreover surgeons are generally not receptive to unfamiliar technologies, especially when they have to deal with energy sources and their possible complications. On the other hand device manufactures usually sponsor many of the studies on energy sources published in the literature and it is difficult for surgeons to make an objective decision of the relative merits of different laparoscopic energy sources.

Blood loss: Concerning blood loss there are 2 RCTs in gynecologic laparoscopy comparing energy sources. Jansen et al. found no difference in estimated blood loss when comparing Ligasure and conventional bipolar forceps for total laparoscopic hysterectomy ( 243.1 vs $273.1 \mathrm{~mL}, \mathrm{p}=0.46)^{47}$. In another study Litta et al, compared Harmonic Scalpel with conventional electrosurgery in laparoscopic myomectomy and they found a significant less blood loss with the ultrasonic device (135.2 vs 182.8 , $\mathrm{p}=0.004)$. The clinical significance though of this result is debatable given the fact that there was no difference in transfusion rates between both groups ${ }^{48}$.

Operating time: Possible operating time reduction could be a major advantage for the use of one energy source over the other. More data are available from general surgery studies. In a Cochrane review of laparoscopic colectomies, the operating time was 40 minutes shorter with advanced bipolar technologies than with monopolar scissors ${ }^{49}$. Similar results come from another meta-analysis in the general surgery, where Ligasure was associated with a shorter operating time compared with monopolar electrocautery or suture $(28 \% \text { reduction, } \mathrm{p}<0.0001)^{50}$. On the other hand findings from studies in gynecology have been inconsistent. Lee et al, reported that Gyrus PK was associated with a time saving of 57 minutes compared with conventional bipolar when used for laparoscopic radical hysterectomy (229 vs $172 \mathrm{~min}, \mathrm{p}<0.001)^{51}$. Moreover the use of Harmonic Scalpel managed to reduce operating time on laparoscopic myomectomies comparing with conventional bipolar electrosurgery $(71.8 \text { vs } 88.8, \mathrm{p}<0.001)^{48}$. However other studies on vaginal assisted and total laparoscopic hysterectomy, revealed no difference in operating time when Ligasure and simple bipolar where compared. $(47,52)$ It seems that the use of vessel sealing devices may show a time-sparing effect when they are used on more complexed operations with a significant amount of large vessels to seal (colectomy, radical hysterectomy). For simple uncomplicated TLH conventional bipolar is more than enough with the advantage of low cost.

Complications: There is only one study in gynecologic laparoscopy a reduction in complication rate was reported with the use of Gyrus PK comparing to conventional bipolar. There was 1 intraoperative complication in the bipolar group with a rectal perforation occurring during right ureterosacral ligament dissection in a patient submitted to radical laparoscopic hysterectomy. Moreover 4 postoperative complications where reported in the same group, including 2 cases of intestinal obstruction, 2 renal failure and 1 vesicovaginal fistula ${ }^{51}$.

Lateral thermal spread: Lateral thermal spread has been studied in laboratory and animal studies. It is reported that temperatures above $42{ }^{\circ} \mathrm{C}$ may cause tissue damage. The degree of lateral thermal 
spread from Ligasure, Harmonic scalpel, conventional bipolar and monopolar hook at similar settings was compared in an ex vivo study using porcine muscle. The temperature at the tip of monopolar was 100.1C, Harmonic ACE $71.3^{\circ} \mathrm{C}$, bipolar and Ligasure $50^{\circ} \mathrm{C}$. Moreover it is required 55seconds for the tip of the monopolar hook to cool to $42^{\circ} \mathrm{C}$, longer than any other device $^{30}$. It is therefore imperative for the surgeons to allow adequate time for cooling of the instrument tips before touching delicate organs. Injury can also be caused if the instrument tip is used for tissue handling when it is still hot after activation. For example, the device head of Ligasure was found to be hot enough to cause injury $\left(45^{\circ} \mathrm{C}\right)$ for 14 seconds after activation ceased and even at 20 seconds after activation the Harmonic can increase tissue temperature by $24^{\circ} \mathrm{C}^{53,54}$. Injuries have been reported from the overheated active blade of the Harmonic inadvertently touching bowel after activation of the energy ceased, causing an ischemic lesion that was undetected during the time of the operation ${ }^{55}$.

Surgeons may reduce lateral thermal spread by avoiding prolonged device activation, using the lowest energy settings or apply irrigation fluid after device activation. Zorn et al applied irrigation fluid to Enseal after the device activation in 20 robotic radical prostatectomies and reported that application of cold $\left(<4^{\circ} \mathrm{C}\right)$ saline reduced that lateral thermal spread from 0.98 to $0.31 \mathrm{~mm}(\mathrm{p}<0.0002)^{56}$.

\section{Conclusions}

A number of different energy sources and devices are available to facilitate laparoscopic operations performance. No particular technology is suited for all tasks and surgeons need to be aware of the limitations of the energy source they choose to use. Availability, training, cost and surgeon's preference are some of the factors that contribute to surgeons choice for a specific energy device over another. Having though a fundamental knowledge of biophysics and the limitations of each device is important in order to choose the most appropriate instrument and minimize the occurrence of electrosurgical injuries. Finally it is clear that adequately powered clinical trials with direct comparison of various energy sources are required in order to guide surgeons in choosing the correct energy for each laparoscopic operation.

\section{References}

1. Wu JM, Wechter ME, Geller EJ, et al. Hysterectomy rates in the United States, 2003 Obstet Gynecol. 2007 Nov; 110(5):1091-5.

2. Morris AR, Siow A. Basic electrosurgical knowledge among practicing gynecologists: a multinational survey. J Am AssocGynecolLaparosc. 2004;11:S8.

3. Mayooram Z, Pearce S, Tsaltsas J, et al. Ignorance of electrosurgery among obstetricians and gynecologists. Br J ObstetGynecol. 2004;111:1413-1418.

4. Feldman LS, Fuchshuber P, Jones D et al. Surgeons don't know what they don't know about the safe use of energy in surgery. Surgical Endosc 2012

5. Feldman LS, Brunt LM, Fuchshuber P, et al. Rationale for the fundamental use of surgical Energy ${ }^{\mathrm{TM}}$ (FUSE) curriculum assessment: focus on safety. SurgEndosc 2013; 27:4054.

6. Sutton C, Abbott J. History of power sources in endoscopicsurgery. J Minim Invasive Gynecol. 2013;20:271-278.

7. Bovie W, Cushing H. Electro-surgery as an aid to the removal of intracranialtumors with a preliminary note on a new surgical-current generator. SurgGynecolObstet. 1928;47:751-784.

8. Thomson AJM. Physical properties of electricity. JMIG 2013

9. Vilos GA, Rajakumar C. Electrosurgical generators and monopolarand bipolar electrosurgery. J Minim Invasive Gynecol.2013;20:279-287.

10. Wang K, Advincula AP. "Current thought" in electrosurgery. Int J GynecolObst. 2007;97:245-250.

11. Massarweh NN, Cosgriff N, Slakey DP. Electrosurgery: history,principles, and current and future uses. J AmCollSurg. 2006;202:520-530

12. Prablu AS, Heniford BT. Energy Sources in Laparoscopy. Minim Invas Cancer Manag. 2013

13. W.K. Winer, A.A. StepanionTrends in laparoscopic electrosurgeryPerioperNursClin, 2 (2) (2007), pp. $145-154$ 
14. LivaditisGJ. Comparison of monopolar and bipolar electrosurgicalmodes for restorative dentistry: a review of the literature. J ProsthetDent. 2001;86:390-399.

15. D. Pandey, C.-F. Yen, C.-L. Lee, et al. Electrosurgical technology: quintessence of the laparoscopic armamentariumGynecol Minim Invasive Ther, 3 (3) (2014), pp. 63-66

16. Newcomb WL, Hope WW, Schmelzer TM, et al. Comparison of blood vessel sealing among new electrosurgical and ultrasonic devices. SurgEndosc. 2009;23:90-96

17. Park CW, Portenier DD. Bipolar electrosurgical devices. In: Feldman LS, editor. The SAGES Manual on the Fundamental Use of Surgical Energy (FUSE). New York: Springer; 2012. p. 93-106

18. Katsuno G, Nagakari K, Fukunaga M. Comparison of two different energy-based vascular sealing systems for the hemostasis of various types of arteries: a porcine model- evaluation of LigaSureForceTriad ${ }^{\text {TM }}$. J Laparoendosc Adv Surg Tech A. 2010;20:747-751.

19. Smith R, Pasic R. The role of vessel sealing technologies in laparoscopic surgery. Surg Technol Int. 2008;17:208-12

20. Albert M, Biest S, Neal Ellis C Jr, et al. Clinical advancements with ENSEAL energy delivery device. 2011. Available at: http://www.ethicon.com/ sites/default/files/Product/Energy/ Group $\% 20$ landing $\% 20$ page/ENSEAL-clinical-advancementsspecial-report-DSL.11-0608.GSN_.SR_.pdf. Accessed February 22, 2013.

21. Munro MG. Economics and energy sources. J MinimInvasiveGynecol.2013;319-327.

22. Amaral JF. The experimental development of an ultrasonically activated scalpel for laparoscopic use. SurgLaparoscEndosc.1994;4:92-99.

23. Gossot D, Buess G, Cuschieri A, etal. Ultrasonic dissection for endoscopic surgery. The E.A.E.S. TechnologyGroup. SurgEndosc. 1999;13:412-417.
24. Bittner JG, VerelaJE, Herron D. Ultrasonic energy systems. In: Feldman LS, editor. The SAGES Manual on the Fundamental Use of Surgical Energy (FUSE). New York: Springer; 2012. p. 123-132.

25. Lyons SD, Law KS. Laparoscopic vessel sealing technologies.J Minim Invasive Gynecol. 2013;20:301-307.

26. Bandi G, Wen CC, Wilkinson EA, et al. Comparison of blade temperature dynamics after activation of Harmonic Ace scalpel and the Ultracision Harmonic Scalpel LCS-K5. J Endourol. 2008;22:333-336.

27. Clements RH, Palepu R. In vivo comparison of the coagulation capability of SonoSurg and Harmonic Ace on $4 \mathrm{~mm}$ and $5 \mathrm{~mm}$ arteries. SurgEndosc. 2007;21:2203-2206.

28. H.H. Kuo, Y. Li, C.J. Wang, H.T. Juang, et al. A casecontrolled study comparing harmonic versus electrosurgery in laparoscopic myomectomy Taiwan J ObstetGynecol, 56 (1) (2017), pp. 73-76

29. Entezari K, Hoffmann P, Goris M, Peltier A, Van Velthoven R. A review of currently available vessel sealing systems. MinimInvasiveTherAlliedTechnol. 2007;16:52-57.

30. Sutton PA, Awad S, Perkins AC, Lobo DN. Comparison of lateral thermal spread using monopolar and bipolar diathermy, the Harmonic Scalpel and the Ligasure. Br J Surg. 2010;97:428-433

31. Kim FJ, Sehrt D, Pompeo A, Molina WR. Comparison of surgical plume among laparoscopic ultrasonic dissectors using a real-time digital quantitative technology. SurgEndosc. 2012;26:3408-3412.

32. G. Sankaranarayanan, R.R. Resapu D.B. Jones, S. Schwaitzberg, S. De Common uses and cited complications of energy in surgery. SurgEndosc, 27 (9) (2013), pp. 3056-3072

33. G. Obonna, R. Mishra Differences between Thunderbeat, LigaSure and Harmonic scalpel energy system in minimally invasive surgery. World J Lap Surg, 7 (2014), pp. 41-44 
34. Nezhat C, Slegler A, Nezhat F, et al. Operative Gynecologic Laparoscopy: Principles and Techniques. 2nd ed. NewYork:McGraw-Hill; 2000.

35. Link WJ, Incropera FP, Glover JL. A plasma scalpel: comparison of tissue damage and wound healing with electrosurgical and steel scalpels.Arch Surg. 1976;111:392-397.

36. Madhuri T, Papatheodorou D, Tailor A, Sutton C, Butler-Manuel S. First clinical experience of argon neutral plasma energy in gynaecological surgery in the UK. GynecolSurg. 2010;7:423-542.

37. Roman H, Auber M, Mokdad C, et al. Ovarian endometrioma ablation using plasma energy versus cystectomy: a step toward better preservation of the ovarian parenchyma in women wishing to conceive. FertilSteril. 2011;96:1396-1400.

38. Odell RC. Pearls, pitfalls and advancement in the delivery of electrosurgical energy during laparoscopy. In: Amaral J, Soper NJ, editors. Problems in General Surgery. Philadelphia: Lippincott Williams \&Wilkins; 2002.

39. Odell RC. Surgical complications specific to monopolar electrosurgical energy: engineering changes that have made electrosurgery safer. J Minim Invasive Gynecol. 2013;20:288-298.

40. Odell RC. Electrosurgery With REM. MedicalElectronics; February1984.pg. 107-109.

41. Clinical perspective: the risk of laparoscopic electrosurgery. ECRI Institute/Health Devices January 1995;24:1.

42. Montero PN, Robinson TN, Weaver JS, et al. Insulation failure in laparoscopic instruments. SurgEndosc. 2010;24:462-465.

43. Yazdani A, Krause H. Laparoscopic instrument insulation failure: the hidden hazard. J Minim Invasive Gynecol. 2007;14:228-232.

44. Vancaillie TG. Active electrode monitoring. How to prevent unintentional thermal injury associated with monopolar electrosurgery at laparoscopy. SurgEndosc. 1998;12:1009-1012.
45. Brill AI, Feste JR, Hamilton TL, et al. Patient safety during laparoscopic monopolar electrosurgeryprinciples and guidelines. Consortium on Electrosurgical Safety During Laparoscopy. J SocLaparoendosc Surg. 1998;2:221-225.

46. Abu-Rafea B, Vilos GA, Al-Obeed O, et al. Monopolar electrosurgery through single-port laparoscopy: a potential hidden hazard for bowel burns. Minim Invasive Gynecol. 2011;18:734-740.

47. Janssen PF, Brolmann HAM, van Kesteren PJM, et al. Perioperative outcomes using LigaSure compared with conventional bipolar instruments in laparoscopic hysterectomy: a randomised controlled trial. BJOG. 2011;118:1568-1575.

48. Litta $\mathrm{P}$, Fantinato $\mathrm{S}$, Calonaci F, et al. A randomized controlled study comparing harmonic versus electrosurgery in laparoscopic myomectomy. FertilSteril. 2010;94:1882-1886

49. Tou S, Malik AI, Wexner SD, Nelson RL. Energy source instruments for laparoscopic colectomy. Cochrane Database Syst Rev. 2011;(5):CD007886

50. Macario A, Dexter F, Sypal J, Cosgriff N, Heniford BT. Operative time and other outcomes of the electrothermal bipolar vessel sealing system (LigaSure) versus other methods for surgical hemostasis: a metaanalysis. SurgInnov. 2008;15:284-291.

51. Lee C-L, Huang K-G, Wang C-J, Lee P-S, Hwang L-L. Laparoscopic radical hysterectomy using pulsed bipolar system: comparison with conventional bipolar electrosurgery. GynecolOncol. 2007;105:620-624.

52. Wang C-J, Yuen L-T, Yen C-F, Lee C-L, Soong Y-K. Comparison of the efficacy of the pulsed bipolar system and conventional bipolar electrosurgery in laparoscopically assisted vaginal hysterectomy. J LaparoendoscAdvSurgTech A. 2005;15:361-364.

53. Campbell PA, Cresswell AB, Frank TG, et al. Real-time thermography during energized vessel sealing and dissection. SurgEndosc. 2003;17:1640-1645. 
54. Govekar HR, Robinson TN, StiegmannGV, et al. Residual heat of laparoscopic energy devices: how long must the surgeon wait to touch additional tissue? SurgEndosc. 2011;25:3499-3502.

55. Campagnacci R, de Sanctis A, Baldarelli M, et al. Electrothermal bipolar vessel sealing device vs. ultrasonic coagulating shears in laparoscopic colectomies: a comparative study. SurgEndosc. 2007;21:1526-1531.

56. Zorn KC, Bhojani N, Gautam G, et al. Application of ice cold irrigation during vascular pedicle control of robot-assisted radical prostatectomy: EnSeal instrument cooling to reduce collateral thermal tissue damage. J Endourol. 2010;24:1991-1996.
Received 22-7-2019

Revised 2-9-2019

Accepted 11-9-2019 